Revista Iberoamericana. Vol. LXVI, Núm. 190, Enero-Marzo 2000, 63-70

ENTREVISTA A MARÍA ISABEL HERNÁNDEZ GUERRA

POR

Frank Graziano

Connecticut College

Frank Graziano y Norah Giraldi Dei Cas entrevistaron a María Isabel (“Mabel”) Hernández Guerra el 18 de abril de 1993, durante el congreso "Felisberto Hernández: Un Homenaje Internacional”. También participó en la discusión Walter Diconca, hijo de María Isabel y nieto de Felisberto Hernández.

María Isabel (“Mabel”) Hernández Guerra, primogénita de Felisberto Hernández, narra desde una perspectiva privilegiada. Fue el fruto del primer matrimonio, entre los cuatro que contrajo Hernández, un matrimonio fracasado cuyos repercusiones se sienten a través del entero cuerpo literario de Hernández. La madre de Mabel, María Isabel Guerra, fue siempre la gran, idealizada, trágica enamorada de Hernández, la que se le escapó en su juventud y dejó el vacío que Hernández nunca pudo rellenar, ni con muñecas. Tanto en estas observaciones de Mabel como en la obra literaria hernandina, se destaca una lucha triangular de imagos - Hernández, la enamorada, la madre — que siempre dió ímpetu y temática a las narraciones. Mabel suele guardar su silencio, pero en la entrevista a continuación ofrece recuerdos íntimos que revelan claves biográficas que han quedado ignoradas o enterradas debajo de los mitos corrientes. Los comentarios de Mabel no sólo iluminan los textos casi autobiográficos de su padre, sino que bosquejan el proceso psicológico por el cual Hernández transformó su mundo angustioso en un habitable refugio ficticio.

\title{
Frank Graziano
}

María Isabel Hernández: La separación de mis padres fue más temprana de lo que ustedes suponen; yo todavía no había nacido. Después de la separación de la que él habla en Tierras de la memoria cuando dice “dejé a mi mujer en la mitad de una pesada espera”, ya no volvieron a convivir. Mi madre [María Isabel Guerra, primera esposa de Felisberto Hernández] quedó con la familia de él, y ella cuenta que le era sumamente penoso vivir con la familia de él por múltiples razones; especialmente con la madre de él, una mujer extremadamente dominante. No sé si dominante es la palabra adecuada —era el tipo de persona que siente que está en el planeta para dirigir la vida de todo el mundo, especialmente la de su familia. Cuando ella quedó sola, porque mi padre se fue a provincia por sus conciertos, la situación se le hizo intolerable y regresó a casa de mi abuela materna. O sea, que cuando yo nací mi padre no estaba ahí. 
Lo que ustedes me preguntan sobre la imagen que me formé de él, era, desde luego, una imagen a través de mi madre y de la familia de mi madre. Mi madre, cuando estaba serena, decía que él era un hombre bueno, que el grave problema había sido su madre y la convivencia — que él no había sido veraz, que le había planteado que iban a vivir solos y ella tuvo que sumarse a esa vida de familia que le fue muy difícil. Además, ella estaba acostumbrada a un mínimo de comodidades materiales; para decirlo rapidamente, era de la pequeña burguesía. Una mujer que esperaba un hijo en su familia y en su clase preparaba cosas como creo que hemos hecho todas cuando esperamos un hijo. El hecho es que ella veía con desesperación que llegaba el momento de tener a su bebé y no tenía nada. Entonces, regresó a casa de sus padres. Parece que nadie le preguntó demasiado, ella llegó llorando, la aceptaron, la acogieron ahí y siguió viviendo con su madre y su familia en Maldonado.

Pero, volviendo a la imagen de Felisberto por el lado de mi familia materna, mi madre percibía en Felisberto destellos de originalidad que admiraba; pero sentía un fastidio cercano a la indignación ante alguna idea de él enteramente original que desafiara lo establecido. El le había anunciado que había concebido un principio revolucionario para estudiar el piano: en lugar de someterse a la práctica de tediosos ejercicios, abordar directamente pasajes de las obras de los grandes músicos. A ella esa idea le pareció una reverenda imbecilidad. Sobre todo, porque si esa fuera "la manera” a alguien se le habría ocurrido antes de ocurrírsele a Felisberto, y la gente no se pasaría tocando escalas y ejercicios de Czerny. Ignoro si esa idea de mi padre tuvo alguna aplicación en música. Pero fuera de toda duda era digna de consideración.

Frank Graziano: ¿Cómo lo veían a Felisberto sus suegros, o sea, los abuelos maternos de usted?

MH: Mi abuelo murió cuando yo tenía un año, de manera que su opinión la desconozco totalmente y, por otra parte, me consta que en la familia había un ambiente machista terrible. Y pese a que sé que fueron discretos al no preguntarle nada a ella, sí hubo una actitud de rechazo tácito hacía él. Como adoraban a mi mamá porque era maestra de escuela y era áurea y blonda y encarnaba la delicadeza femenina, automáticamente al separarse, mi padre quedaba como el canalla, sin averiguar mucho más, o nada más. Y creo que con mis tíos, los hermanos de mi madre, pasó algo así; tenían un rechazo muy grande por él. Una vez uno de ellos le dijo: "Tu escribes esas cosas porque no te dieron unas buenas palizas cuando chico”. Y el dijo: “Al revés, porque me dieron demasiadas”. Ese lenguaje simple de él, desconcierta mucho a los que creen que la literatura es "en mi patria hay primorosos campos esmaltados de florecillas donde pacen las beatíficas vacas”. Eso sí es literatura. O los cuentos con rubias y cadáveres. Y no perciben todo lo que hay detrás de la aparente simplicidad de las palabras de Felisberto. Creo que mucha gente, incluso en este momento, debe pensar eso, gente que se acerca por el renombre exterior, abre un libro de Felisberto, encuentra palabras comunes pero el significado no lo percibe. Entonces les parece que si ellos no encuentran nada, es porque no hay nada; y en el reconocimiento de su obra ven algo fraguado, un enigma irritante. Mis tíos estaban en esa posición, cargada además de una hostilidad más o menos manifiesta. No se hablaba con demasiada frecuencia de él, pero cuando afloraba el tema, había hostilidad.

FG: Pero ¿a qué se debía? ¿Cuál fue el motivo de ese rechazo? 
MH: Mira, no puedo saber cómo ellos exactamente lo veían, pero mi madre me contaba que ella se sintió seducida, que ella se sintió seducida sobre todo por el intelectual. Ella vivía en un medio provinciano y tenía ciertas apetencias, inquietudes artísticas e intelectuales que en un medio provinciano eran muy difíciles de satisfacer. Entonces, aparece este personaje que a ella se le presentó por su lado serio: le hablaba de Carlos Vaz Ferreira, de la filosofía, del arte, de la música - ella ya había estudiado música durante mucho tiempo, yo tengo todavía el piano de ella. Entonces, a ella la sedujo ese Felisberto. Y que la historia me perdone si me meto con algo demasiado íntimo, pero mi madre me contó que la noche anterior al matrimonio tuvo una sorpresa tan impresionante que no se arrepintió de la boda por cobardía, porque estaba el vestido de novia y toda la familia alrededor y las invitaciones de casamiento ya enviadas. Parece que a mi padre, con esa personalidad múltiple que tenía, que a mi me parece una maravilla, pero a ella le pegó el susto del siglo, se le ocurrió ponerse un batón — una bata de casa — de mi abuela y ponerse a brincar por arriba de las mesas, porque estaba feliz. Entonces, eso a mi madre le causó un trauma fenomenal y no se atrevió a decirlo. Creo que también para ellos, los de su familia, una actitud así ponía en descubierto a un impostor. La impresión que ella tuvo fue de que ese hombre era un desconocido; ella había conocido a un caballero docto y, de repente, aparecía allí una especie de payaso que ella no podía aceptar, pero al cual tampoco le podía decir: "Mira, vamos a dejar esto para otro día”. Entonces igual se casó. Y, a partir de ahí, siguieron esos equívocos constantes. Por ejemplo, durante el viaje de Maldonado a Montevideo — que ahora se hace en un rato y en un omnibus común, en aquella época era un señor viaje- y él fue canturreando el Carnaval de Schuman durante todo el camino. Y cuando llegaron, ella no podía más y le dijo: "No puedo más oir esas notas repetidas". Y el le dijo: "Pero querida, yo lo hacía porque pensaba que después ibas a asociar este viaje tan lindo con esta música”. Había un desacomodo irremediable. Sin ninguna duda, el gran desacomodo fue en el terreno de disfrutar del amor porque mi madre, y todas mis tías, fueron terrible y brutalmente reprimidas por la educación de la época, de su madre y de los alrededores.

Norah Giraldi Dei Cas: ¿En que momento Felisberto volvió a hablar contigo de tu madre?

$M H$ : Bueno, yo a él lo ví, durante mi infancia —retomo el hilo de las veces que tuve contacto con él_ durante mi infancia hay una foto que me muestra de poquitos meses en brazos de él. Luego, hay una aparición de mi abuela paterna, de ese personaje que causó tantas dificultades en la familia, no sólo a nosotros. Recuerdo esa aparición porque me regalaron un piyamita verde con un ribete de flores chiquititas y recuerdo cada rayita de la tela con un placer enorme. Y luego el recuerdo difícil, el momento difícil que estoy evocando ahora, de cuando yo tenía unos cuatro años. En ese período, Felisberto apareció y pasó algo que recuerdo con mucha incomodidad. El fue a Maldonado a ver a mi madre. Se pusieron a conversar, en una conversación que evidentemente me excluía por completo. Yo tenía una obvia apetencia de papá y en un momento dado los interrumpí. Entonces, él me levantó en brazos y me encerró en una piecita de juguetes para que no molestara. Y yo me quedé profundamente dormida, a lo Desdémona: con este lío no puedo, me duermo. Y se acabó.

Más tarde, cuando yo tenía seis años, estábamos todavía en provincia con mi madre y él apareció nuevamente. Primero le escribió, diciéndole que después de tantos años de vivir 
separados él pensaba que era más ajustado a la realidad pensar ya en el divorcio. Y entonces a ella le empezaron los escrúpulos, fue a consultar a la anciana venerable del pueblo, buscando un consejo concreto; pero la anciana venerable del pueblo, doña Virginia, le dijo que se encomendara a la Virgen, lo cual mi mamá entendió que no servía para nada, pero en fin... El asunto es que sí accedió a divorciarse. A partir de ahí, un gran vacío. Hasta que a los dieciséis años, me pongo a leerlo y me despierta una pasión tan enloquecida lo que el escribía, como si mis propias voces, las más íntimas, de repente cobraran forma y vida. Fue así un deslumbramiento y no me atrevía a decir en mi casa que quería verlo, porque había unas historias que hoy parecen absurdas, como que mi familia era "blanca" y él era “colorado”. Creo que sólo un uruguayo, o gente que haya vivido realidades parecidas, puede entender que ser blanco o colorado no significaba una opción política, significaba como si se tuviera, como los animales tienen un pelaje, un pelaje interno: soy “blanco" o “colorado”.

NG: Un bando de lucha.

$M H$ : Pero una cosa incorporada totalmente a lo que era la vida personal y familiar, que te marcaba. Un buen día dijeron "porque tú eres blanca”. Y a mi se me ocurrió decir: “yo no sé si soy blanca, cuando sea grande entenderé que quiere decir eso y decidiré”. Eso provocó la alarma familiar más espantosa. "Felisberto la debe ir a ver a la escuela, la debe ver en secreto, le está metiendo ideas coloradas”. Desgraciadamente, Felisberto no me iba a ver a la escuela, ni me metía ideas coloradas ni de ninguna clase.

NG: ¿Cómo volviste a él?

$M H$ : Porque él, por suerte, después me contó que muchas veces había intentado acercarse pero sentía una especie de cobardía frente a esa familia que sabía hostil. Como un año y medio después de que yo empezara a leerlo, a él se le ocurrió escribirle a mi madre de manera muy respetuosa — eso conmovió al clan de mi mamá— diciéndole: "si todavía tienes tan buena voluntad como para que yo vea a Mabel, quisiera verla”. A todas estas, yo ya me estaba por casar. Era un período complicado por eso de los preparativos del casamiento. Ese clima tan especial que, dieciocho años antes, le impidiera a mi madre decir “no”. ¡Que bueno, los preparativos del casamiento! Si no, yo no estaría aquí, puesto que a mi madre la hicieron seguir adelante. Ahora, como estábamos metidos ya en ese lío de la iglesia y demás, se nos ocurrió decirle que bueno, que se acercara en el momento en que yo me casara y ya le mandamos las invitaciones. De esa manera, además — creo que yo participé en esa decisión - me pareció que era la manera de iniciar una relación con él, cuando ya no estuviera el peso y el lastre de toda la familia alrededor opinando. Fue muy lindo todo lo que me dijo respecto al día en que llegó a la iglesia—lo cual no era su costumbre precisamente, y después él me preguntó mucho que hacía yo en la iglesia. Yo tuve una maestra de literatura que predicó los evangelios de una manera que convertía las piedras; tuve salidas y entradas en el catolicismo. En la época en que me reencontré con Felisberto, cuando me casé, estaba en una de esas entradas y salidas del catolicismo. Y un día él se puso a preguntarme: "Bueno, ¿y que es lo que crees, que es lo que sientes en la iglesia?” “Ay mira, me encanta. Toda esa púrpura del imperio romano que heredó la iglesia católica me parece una maravilla, y los cantos, y las pinturas, y haberme puesto ese vestidazo”. “¡Ah! ¡te gusta el teatro de la iglesia!” "Pues sí”. Y fue muy lindo todo lo que me contó de lo que sintió ese día. El tampoco me conocía en absoluto. 
$N G$ : El buscaba a la novia.

MH: Lo que pasa es que los sábados era el día en que tradicionalmente se casaba todo el mundo allá en Montevideo. Entonces, el llegó a la iglesia puntualmente —el pobre inocente- 0 , tal vez un poco antes de la hora, y vió entrar una muchacha, que no era yo una novia equis - entonces pensó: "ipor algo toda la vida he estado contra esas idioteces de ‘la voz de la sangre’! ¿Qué me dice a mí mi sangre de esa muchacha? Nada”. Hasta que, cuando llegó el turno del casamiento mío, entonces se dió cuenta de que, además de que finalmente la voz de la sangre sí le decía algo, estaba mi tío que era el padrino, y todo un montón de gente que el conocía. Y luego comentó mucho una mirada que le eché al padre de mis hijos, que lo hizo acordar a la manera que tenían de mirar sus hermanas y quería decir algo como "bueno, querido, ya estamos aquí, en el escenario". Que no era una cosa de solemnidad mística ni nada por el estilo. A partir de ahí, nos vimos regularmente, hasta que en los últimos años hubo episodios de interferencias de nuevo de su madre con la mía, y una separación que desgraciadamente fue definitiva. Y no por voluntad mía. El no pudo más, me dijo: “ya no puedo más vivir entre dos odios”. De tal modo, que los últimos años ya practicamente no lo veía.

FG: En sus recuerdos de Felisberto entre el día del matrimonio y el '64, cuando se murió, ¿qué se destaca?

MH: Había ideas que le daban rabia, que lo irritaban; se controlaba y la manera de él de mostrar su control era exagerando una amabilidad tan grande: "pero señora, usted es católica, aah, que bien”. Pero sí le irritaba la aceptación de las ideas preconcebidas, que te las dan y las aceptas sin análisis, usando lo que ya está armado. Eso es la antítesis de su pensamiento, y de su escritura y de todo lo de él. Justamente, creo que parte de lo que es él, de su literatura y de todo, es el ver el mundo sin armar. A ver cómo lo armamos nosotros, cada uno, y no eso que nos han contado. Entonces, la gente que aceptaba la religión porque "mamita me dijo", y encima con razonamientos que el sentía profundamente falaces, lo irritaba por todos lados. Recuerdo, por ejemplo, que contaba de una señora a quien él le preguntó por qué creía en la providencia y todo eso, y ella le dijo: “Ah! pero es que Dios ha sido tan providente. Usted no ve como puso las tripas en el interior del cerdito para que podamos hacer los chorizos".

$N G$ : Era loquísimo. Era ni siquiera loco, era loquísimo de bromas. En ese sentido quise decir.

MH: Yo creo que loquísimo en el otro sentido que dije antes. A mi el universo no me lo dan armado, lo voy a armar yo y no jodan. Creo que era esa su locura. A mucha gente le debe chocar esa desacralización, que es parte del juego de él, el desarmar y armar del mundo. Para él no hay nada sagrado.

FG: Usted mencionó que durante esos últimos años había una tensión entre la Calita [madre de Felisberto] y la madre de usted. ¿Cuál fue exactamente el problema, qué tipo de tensión?

$M H$ : Ah! esa pregunta es muy interesante, porque en realidad fue una lucha de fantasmas. No se vieron nunca más. Pero cada una tenía una imagen tal de la otra que actuaban a través de nosotros. Calita a través de su hijo y mi madre a través de mi. Entonces, se imponían cosas y limitaciones y observaciones. En esa batalla de fantasmas, cada una 
luchaba contra una imagen de la otra congelada desde hacía veinte años y ambas partes nos usaban —a mí, a mis hijos y a Felisberto, es decir, a los que estaban entre ellas - como armas, como rehenes, como trofeos. En eso debo hacerle honor a mi mamá y es que ella siempre me pintó a su suegra como a una bruja. Yo creía que exageraba, y cuando tuve oportunidad de hablar con mis primas, que la habían soportado más de cerca, creo que por el contrario mi madre se quedó corta. Creo que Calita era una persona realmente terrible, terrible. Si algún día quieren escribir páginas negras sobre los antepasados de Felisberto Hernández, podrían preguntarle a mi prima Cristina que vivió con ella.

FG: Sería muy útil si usted pudiera construir una especie de retrato en palabras de cada uno de esos tres personajes - su madre, Calita y Felisberto.

MH: Mi abuela, además de ese lado negativo terrible, el del dominio del prójimo prójimo en los dos sentidos, también en el sentido de los próximos, que es un doblete de prójimo - además de eso, tenía características que a mí me caían simpáticas a través de los relatos de mi madre. Por ejemplo, alguien lo mencionó — creo que tú Norah- esa manera de vivir en la familia que tenían, de sentir determinadas cosas en grupo, y creo que la Calita tuvo mucho que ver en eso porque le encantaba reunir gente y hacer unas fiestas que refundieron a su pobre marido. Mi abuelo Prudencio - lo vi poquísimas veces - tenía una capacidad de expresar la ternura a tal punto que nunca me olvidaré de eso, de la felicidad que mostraba cuando estaba conmigo y el festejar cosas ínfimas que hacemos todos los niños pero que a él le parecían una maravilla. Fue un hombre que se doblegó totalmente a su esposa, y parece que esas fiestas que ella daba y que invitaba a medio mundo y hacía jolgorio y música fue una de las razones de refundirlo económicamente. Mi abuelo Prudencio formaba parte de un consorcio de tres hermanos, constructores, Prudencio, Faustino y Sandalio Hernández. Ellos contrataban y se encargaban de las construcciones, de casas de Montevideo, de las que muchas tienen sólo dos iniciales (F. y S. Hernández) no la de mi abuelo, porque él, era tal su exigencia de dinero, que provenía de la esposa, de la famosa Calita, que los hermanos vieron que su negocio se iba al diablo si seguían dándole y dándole y dándole todo lo que el pedía. Al punto de que se separaron y el quedó ahí al garete. Y afrontó situaciones terribles porque no tenía el valor de decirle a la mujer "no hay más dinero". Felisberto cuenta algo en un cuento, y creo que es en "Mi primer concierto”, de un acreedor que lo persigue con un cuchillo y lo corre al abuelo Prudencio. Y además mi madre contaba cosas realmente grotescas y tristes, por ejemplo que cuando la situación económica llegó al punto más insostenible, Calita le hizo un traje y que el pobre quedó realmente disfrazado, pero salió para la calle con el traje que le cosió su mujer mientras se ocupaba, en fin, de toda esa vida social intensa que le encantaba.

Mi mamá era la maestra de escuela — abnegada, blonda, delgadita, delicada....

WD:...y aristocrática.

MH: Sí, además eso. Como de una superioridad que residía no se sabía bien en qué. Era como si ella hubiera inventado un personaje y después se hubiera metido adentro de él. Al punto de que uno lo sabía cuando realmente estaba expresando algo auténtico. Y creo que de ahí viene una cosa muy fuerte que yo tengo de unión con la figura de mi padre, pese a que lo conocí de una manera tan intermitente y tan llena de dificultades, había en él una fuerza de vida veraz y auténtica, que es lo que a mí me da fuerzas para vivir, finalmente. 
Mi padre evidentemente estaba rebasado por estas mujercitas. La mamá porque era su mamá y lo tenía en el puño y mi madre por toda esa...por todo. Alguien —para simplificar, y uso palabras que creo que son excesivamente simplificadoras pero de alguna manera hay que englobar la cosa, ¿no?- pensaba que ella era paranoica y él esquizofrénico y que entonces en ese juego de agrandamiento de ella y de achicamiento de él, se formaba cierto equilibrio, patológico obviamente, del cual soy fruto. Ahora ese tema de los tres personajes da para mucho, ¿eh? Porque mi padre también acusaba a la familia de ella de ser burguesa y entonces ella decía que había una contradicción en él. Cuando se casaron les dieron una manta para el viaje y el decía "ahora no se la devolvemos, a nosotros nos viene muy bien”, y ella le decía: “¿Cómo? Esta manta es muy burguesa. Si tú desdeñas a los burgueses, tienes que mandarle al César lo que es de César, ¿no?’ Y la tal Calita no sé que sentiría, pero por lo pronto sabía que María Isabel era su rival fuerte, creo, igual que tú, que la más seria de sus rivales, en cuanto al atrapamiento de Felisberto. Mi madre a la tal Calita, además de verla como el monstruo, que creo que efectivamente era, la veía como un ser ordinario. "Imagínate, prepararon la pieza para nosotros que íbamos recién casados, después de haberme dicho que me estaban haciendo una casa y que no era cierto, me llevan ahí, a la casa de Calita, ¿̇y sabes lo que habían puesto en la pieza? Un sillón con un hoyo en el medio, roto, pero disimulado con un almohadón”. Y eso a mi madre le parecía el colmo de lo que ella hubiera llamado chusmería, la ordinariez. No se daba cuenta de que era simplemente pobreza y maneras de ver “cómo arreglamos la cosa”. De manera que es un terceto difícil de imaginar, realmente.

Felisberto era - y es la primera palabra que me vino a la mente cuando me dijiste que dijera algo sobre él- modesto. Ese medio económico como el de mi madre, que no era de gente rica sino simplemente de gente acomodada que puede vivir con cierta holgura, para él era como algo que estaba por encima de él en cuanto a posibilidad. Recuerdo algunos de sus amigos, incluso la familia de Norah, donde creo que encontró una conjunción — que por eso es que yo ante todo tengo hacia ellos un sentimiento de gratitud— - sé que lo que le dieron muy pocas veces se daba conjuntamente: comprensión de su obra, cariño directo a la persona y un lugar donde las cosas transcurrían sin dificultad. Creo que ese era el estrato más alto que él frecuentaba en lo ecónomico, sin ser un estrato tan alto dentro de la sociedad general. Y luego, tenía encuentros, para él fundamentales, con personas, con intelectuales y gente que entendía su obra, pero no muchos. Fundamental, el encuentro con Jules Supervielle.

$W D$ : A Felisberto yo le evoco sentado en unas sillas que lamentablemente ya no existen, que eran de madera con cuero y aquellas mesas de mármol, y cuando él se sentaba en esas sillas era como el complemento indispensable del café. Es decir, allí el café o el restaurante tomaba vida y su presencia era tan fuerte. El me llevaba a comer —él me enseñó a comer-con Reina Reyes, y yo le contaba a mamá de su forma de relacionarse con la gente, que también me la enseñó él; yo dialogo con todo el mundo como lo hacía él. El hablaba con el mozo como si fuera alguien muy conocido y muy querido y lo hacía sentir muy bien y, por lo tanto, a él lo querían enormemente. Entonces, él le pedía las papas blancas al mozo...

MH: Pálidas...

WD: Blancas. Y el mozo se iba y daba la orden en la cocina. Y el esperaba unos minutos — y me acuerdo de esto en la Asociación Cristiana - esperaba unos minutos y había un 
pasaplatos que era relativamente pequeño y el metía su humanidad por ese agujero y hablaba con el cocinero y le advertía que las papas que le habían ordenado eran para él. ¡Cuidado! es decir, él se aseguraba por dos vías de que esas papas fueran perfectas. Y, por supuesto que el cocinero lo reconocía. El sabía quien era y ponía especial cuidado. Y me acuerdo los platos de papas fritas que llegaban a nuestra mesa, eran de orgía.

Cuando Felisberto llegaba a casa, él daba, él te regalaba alegría, porque yo recuerdo que llevó algún regalo, pero el regalo que llevaba era su ser. El se daba, te daba, estaba dando todo el tiempo. Y no era un dar que te agobiaba — querías más, como que te enviciabas con esa cosa de él contagiosa y de alegría.

$N G$ : Es una linda imagen que yo tengo también, de una persona muy generosa. Muy generosa y que entonces te pasa como a mí, yo nunca lo ví angustiado. El hablaba con mi padre y tenían conversaciones; yo sé que había confidencias. Pero él, cuando se ponía a hablar en la mesa y todo, era el hombre jovial.

$M H$ : Pero por cierto que las angustias lo frecuentaban. 